\title{
Quem ganha e quem perde com a falta de proteção aos manguezais? Aspectos da Resolução Conama n³03/2002
}

\author{
Who wins and who loses with the lack of mangroves' protection? \\ Aspects of Conama Resolution $n^{\circ} 303 / 2002$ \\ Ana Lucia Gomes dos Santos* $₫(\mathbb{D}$, Sueli Angelo Furlan $\bowtie$ (ID \\ Departamento de Geografia, Faculdade de Filosofia, Letras e Ciências Humanas, \\ Universidade de São Paulo, São Paulo, SP, Brasil \\ E-mail: sucaangf@usp.br \\ *E-mail para correspondência: analuciasantos@usp.br
}

Recebido (Received): 28/04/2021

\begin{abstract}
Resumo: Quem ganha e quem perde com a falta de proteção aos manguezais? Essa é a pergunta norteadora da pesquisa, que teve como objetivo analisar se a atual legislação ambiental brasileira protege de fato o ecossistema manguezal. Para auxiliar essa reflexão, o presente trabalho utilizou como método a pesquisa documental, apresentando uma retrospectiva sobre a legislação ambiental, com início nas Cartas Régias, promulgadas durante o Brasil Colônia, passando por leis, decretos, resoluções, entre outras normas, até os regulamentos referendados em 2020. Também apresentou o papel do Conselho Nacional do Meio Ambiente - CONAMA, órgão do Ministério do Meio Ambiente responsável por estabelecer critérios para o licenciamento ambiental, controle e manutenção da qualidade do meio ambiente, além disso, analisou o processo de revogação e validação da Resolução Conama n³03/2002. A revogação ocorreu durante a $135^{\mathrm{a}}$ Reunião Ordinária do Conama, em 28 de setembro de 2020, evento que suscitou a referida indagação. A existência de normas legais que regulamentam a conservação dos manguezais é imprescindível para que esse ecossistema continue como Área de Preservação Permanente em toda a sua extensão, conforme previsto na atual legislação ambiental brasileira. A revogação desta resolução pode ser considerada um retrocesso para os direitos ambientais adquiridos. Desta forma, essa norma deve ser mantida, visto a relevância da proteção aos ecossistemas tratados, especialmente os manguezais, devido a sua importância ecológica, social e também econômica.
\end{abstract}

Palavras-Chaves: Mangue; Conservação; Legislação.

Abstract: Who wins and who loses with the lack of mangroves' protection? This is the guiding question of this research, which aimed to analyze whether the current Brazilian environmental legislation actually protects the mangrove ecosystem. To assist this reflection, the current study used the documentary research as a method, presenting a retrospective on environmental legislation, starting from the Royal Letters, promulgated during Colony Brazil, passing by laws, decrees, resolutions, among other rules, up to the regulations endorsed in 2020. It also presented the role of the National Environment Council - CONAMA, an agency of the Ministry of the Environment responsible for establishing the criteria for environmental licensing, control and maintenance of the quality of the environment, in addition, it analyzed the revocation process and validation of Conama Resolution $n^{\circ} 303 / 2002$. The revocation took place during the 135th Ordinary Meeting of Conama, on September 28, 2020, an event that raised this question. The existence of legal norms that regulate the conservation of mangroves is essential for this ecosystem to continue remain as Permanent Preservation Area in all its extension, as determined for in the current Brazilian environmental legislation. The repeal of this resolution can be considered a regression for the acquired environmental rights. In this way, so this rule must be maintained, given the relevance of protection to cited ecosystems, especially mangroves, due to their ecological, social and also economic importance.

Keywords: Mangrove; Conservation; Legislation. 


\section{Introdução}

Os manguezais são considerados um dos ecossistemas mais produtivos do planeta (ICMBio, 2018), mesmo ocupando uma área muito pequena, quando comparado a outros ecossistemas, cobrindo apenas 0,12\% da área total da superfície terrestre (POLIDORO et al., 2010). Desempenham importantes funções ambientais na zona costeira tropical e subtropical.

Entretanto, esse ecossistema não dispõe de proteção adequada no mundo e no Brasil. Dados apresentados no Atlas dos Manguezais do Brasil apontam que pelo menos 25\% dos manguezais brasileiros já não existem mais, considerando o que havia no início do século 20. Em algumas regiões essa diminuição é ainda mais significativa, com perda de 40\% dessa cobertura, como nas regiões Nordeste e Sudeste (ICMBio, 2018).

A destruição dos manguezais também ameaça a existência dos demais ecossistemas costeiros, devido ao impacto aos vários processos funcionais existentes nesse ambiente. Por isso, os manguezais se constituem como objeto de instrumentos legais específicos, elaborados para a conservação desse sistema. Todavia, há no Brasil um processo de desconstrução desse arcabouço legal de proteção, tornando-se fundamental analisar as ameaças desse procedimento, visando a seguridade da conservação aos manguezais.

Uma das ações mais recentes foi a revogação da Resolução Conama n³03/2002, norma legal imprescindível para a conservação desse ecossistema. Dessa forma, faz-se necessário compreender as ações institucionais das alterações da legislação ambiental, uma delas com a diminuição da participação da sociedade nos conselhos definidos em lei, assim como os rebatimentos sobre o avanço da degradação ambiental. A presente pesquisa objetiva analisar se a atual legislação ambiental brasileira protege de fato o ecossistema manguezal.

\section{Materiais e métodos}

Considerando o caráter analítico-descritivo do presente trabalho, foi realizada uma pesquisa documental sobre as normas legais de proteção ambiental, focando na legislação específica para o ecossistema manguezal, assim como em artigos de periódicos, livros sobre o tema e vídeo. O estudo também contemplou a investigação em sites oficiais, seleção de conteúdo, organização das informações, análise e elaboração de sínteses.

De acordo com Sá-Silva, Almeida e Guindani (2009), na etapa chamada análise dos documentos é proposta a produção ou reelaboração de conhecimentos, como novas formas de compreensão do fenômeno investigado. Desse modo, torna-se fundamental a interpretação, a contextualização das informações e a síntese na elucidação do fenômeno investigado.

A primeira leitura para a seleção das normas investigadas foi o capítulo "Arcabouço legal de proteção aos manguezais", presente no Atlas dos Manguezais do Brasil (ICMBio, 2018). Posteriormente, realizou-se a leitura de cada uma dessas normas, como também das que as sucederam, seja alterando ou revogando. Durante a leitura selecionou-se trechos para cotejamento reflexivo comparativo.

A pesquisa documental da legislação brasileira de proteção aos manguezais teve início nas Cartas Régias promulgadas durante o Brasil Colônia, passando por leis, decretos, resoluções, entre outros, até os regulamentos aprovados em 2020. Examinou-se as características da evolução desses preceitos legais e seus propósitos, comparando os aspectos mais e menos restritivos nos instrumentos legais para a conservação desse ecossistema.

Além disso, foi analisado o vídeo da $135^{\mathrm{a}}$ Reunião Ordinária do Conama (CONAMA, 2020), onde ocorreu a revogação da Resolução n ${ }^{\circ} 303 / 2002$ e a proposição da Resolução $n^{\circ}$ 500/2020. Dessa narrativa institucional destacou-se a fala de diferentes membros do conselho. Por fim, também verificou-se os desdobramentos judiciais posteriores: despachos, decisões e medida cautelar.

A análise documental favorece a observação do processo de maturação ou evolução de um conceito ou prática (CELLARD, 2008), foi utilizada na presente pesquisa com o intuito de verificar de que forma a legislação ambiental brasileira vem, ao longo dos anos, protegendo ou não o ecossistema manguezal.

\section{Retrospectiva da legislação brasileira sobre os manguezais}

Para compreender os esforços institucionais de proteção ao ecossistema manguezal no Brasil, apresentase uma breve retrospectiva das normas legais. 
A proteção aos manguezais é antiga na legislação brasileira. Maciel (2001) considera que uma das primeiras normas de proteção ocorreu por meio do Decreto de 05 de março de 1664, que proibiu a concessão de áreas alagadas e pantanosas (lezírias e pauis). Quatorze anos depois, em 04 de dezembro de 1678, a Carta Régia determinou os manguezais como áreas pertencentes à Coroa e imunes à corte.

Mais adiante, o Regimento de 24 de julho de 1704, reafirma as terras aluviais (mangue) como áreas pertencentes à coroa, proibindo sua doação. A Carta Régia de 21 de outubro de 1710, determinava que as sesmarias não deveriam compreender os terrenos de marinha, devendo estar desimpedidos para serviços e defesa. Em 1760, o Alvará de 10 de julho, com força de lei foi mais rigoroso, determinava multa e prisão a quem cortasse mangues (MACIEL, 2001). Nesse período a casca do mangue era utilizada em curtumes, para extração do tanino.

É evidente que todos esses regimentos, definidos durante o Brasil Colônia, não tinham como intenção a conservação ambiental e sim o resguardo de um recurso natural abundante nos mangues, o tanino. Essa substância química, utilizada para curtir couro, era um dos itens vendidos para outros países nesse período. Portanto, o principal objetivo desses regimentos era assegurar o recurso econômico utilizado pela Coroa.

Com a independência do Brasil em 1822, o governo imperial criou a categoria terrenos de marinha, demarcados pela Lei de 15 de novembro de 1831. Posteriormente, o Decreto $\mathrm{n}^{\circ} 4.105$ de 22 de fevereiro de 1868 , em seu artigo $1^{\circ}$ estabeleceu os terrenos de marinha como as áreas situadas a trinta e três metros do litoral, sendo a referência a linha de preamar média de 1831, acrescidos das áreas onde havia influência das águas salgadas. Os terrenos de marinha são propriedades da União, todos os ecossistemas situados nessa área permaneceram de certa forma protegidos, entre eles os manguezais, que só podem ser encontrados sob influência das marés.

O Decreto ${ }^{\circ} 14.596$ de 31 de dezembro de 1920, estabeleceu critérios para o arrendamento de áreas de manguezais, de propriedade da União, mas manteve a proteção para a faixa de trinta e três metros, proibindo qualquer forma de utilização do manguezal existente nessa zona.

Em 23 de janeiro de 1934, o Decreto n²3.793, considerado o primeiro Código Florestal do Brasil, criou a categoria de florestas protetoras, aquelas que auxiliam na conservação do regime das águas, na prevenção da erosão ou na fixação de dunas. Sendo assim, os manguezais foram enquadrados como florestas protetoras.

O Decreto $\mathrm{n}^{\circ} 24.643$ de 10 de julho de 1934, conhecido como Código de Águas, manteve as normas para os terrenos de marinha como patrimônio da União, mas permitiu o seu uso pelas comunidades locais.

Em 05 de setembro de 1946, o Decreto-Lei $n^{\circ} 9.760$ reafirmou os terrenos de marinha e seus acrescidos como bens imóveis da União.

Um marco na legislação ambiental brasileira foi a promulgação da Lei $n^{\circ} 4.771$, de 15 de setembro de 1965, chamada de Novo Código Florestal, no seu artigo $2^{\circ}$ estabeleceu a categoria Área de Preservação Permanente (APP), incluindo nessa categoria as restingas, como fixadoras de dunas ou estabilizadoras de mangues.

Em 18 de setembro de 1985, o Conama aprovou a Resolução n4 que considerou os manguezais como Reservas Ecológicas e definiu o conceito de manguezal como: "ecossistema litorâneo que ocorre em terrenos baixos sujeitos à ação das marés localizadas em áreas relativamente abrigadas e formado por vasas lodosas recentes as quais se associam comunidades vegetais características". Essa definição considerou apenas como manguezal as áreas cobertas pelos bosques de mangue e não todas as suas feições, como os lavados e os apicuns.

A Constituição Federal de 1988 estabeleceu a lei maior de proteção ao meio ambiente no Brasil, o artigo $225^{\circ}$ determina: "Todos têm direito ao meio ambiente ecologicamente equilibrado, bem de uso comum do povo e essencial à sadia qualidade de vida, impondo-se ao Poder Público e à coletividade o dever de defendê-lo e preservá-lo para as presentes e futuras gerações". A Constituição protegeu os manguezais, ao definir a Mata Atlântica e a Zona Costeira como Patrimônio Nacional, sendo que sua utilização deve ser feita na forma da lei, com condições que assegurem sua preservação, como previsto no parágrafo $4^{\circ}$ do referido artigo.

No mesmo ano, a Lei $\mathrm{n}^{\circ} 7.661$ de 16 de maio de 1988 instituiu o Plano Nacional de Gerenciamento Costeiro. $\mathrm{O}$ artigo $3^{\circ}$ prevê o zoneamento priorizando a conservação e a proteção de alguns bens, entre eles restingas, dunas e manguezais.

O Decreto $\mathrm{n}^{\circ} 750$ de 10 de fevereiro de 1993, artigo $3^{\circ}$, afirma que o manguezal é um ecossistema associado à Mata Atlântica garantindo, dessa forma, a mesma proteção dada ao Bioma. 
Em $1^{\circ}$ de outubro de 1993, a Resolução Conama $n^{\circ} 10$ (alterou a Resolução ${ }^{\circ}$ 4/1985), estabeleceu parâmetros para a análise dos estágios de sucessão da Mata Atlântica e apresentou no artigo $5^{\circ}$ a seguinte definição de manguezal:

I - Manguezal - vegetação com influência flúvio-marinha, típica de solos limosos de regiões estuarinas e dispersão descontínua ao longo da costa brasileira, entre os Estados do Amapá e Santa Catarina. Nesse ambiente halófito, desenvolve-se uma flora especializada, ora dominada por gramíneas (Spartina) e amarilidáceas (Crinum), que lhe conferem uma fisionomia herbácea, ora dominada por espécies arbóreas dos gêneros Rhizophora, Laguncularia e Avicennia. De acordo com a dominância de cada gênero, o manguezal pode ser classificado em mangue vermelho (Rhizophora), mangue branco (Laguncularia) e mangue siriúba (Avicennia), os dois primeiros colonizando os locais mais baixos e o terceiro os locais mais altos e mais afastados da influência das marés. Quando o mangue penetra em locais arenosos denomina-se mangue seco.

Essa definição de manguezal é mais abrangente do que a anterior (Resolução $n^{\circ} 4 / 1985$ ), entretanto, continuou associando o manguezal apenas a sua flora, ou seja, abrangendo somente o bosque de mangue, não considerando as feições lavado e apicum como integrantes do sistema.

O Decreto ${ }^{\circ} 1.905$ de 16 de maio de 1996, promulga a Convenção sobre Zonas Úmidas de Importância Internacional, especialmente como habitat de aves aquáticas, mais conhecida como Convenção de Ramsar de 1971, fazendo valer sua execução integral para a proteção desses ambientes.

No intuito de estabelecer sanções penais e administrativas a quem cometer atividades lesivas ao meio ambiente foi sancionada a Lei ${ }^{\circ} 9.605$ de 12 de fevereiro de 1998 , onde estabeleceu-se no artigo $50^{\circ}$ pena de multa e detenção de três meses a um ano para quem destruir ou danificar florestas nativas ou plantadas, como vegetação fixadora de dunas e protetoras de mangue.

Em 20 de março de 2002, o Conama aprovou a Resolução n³03, estabelecendo parâmetros, definições e limites para as Áreas de Preservação Permanente. Também apresentou uma nova definição para o ecossistema manguezal, revogando a Resolução ${ }^{\circ} 4 / 1985$. O artigo $2^{\circ}$ define manguezais como:

Ecossistema litorâneo que ocorre em terrenos baixos, sujeitos à ação das marés, formado por vasas lodosas recentes ou arenosas, às quais se associa, predominantemente, a vegetação natural conhecida como mangue, com influência flúvio-marinha, típica de solos limosos de regiões estuarinas e com dispersão descontínua ao longo da costa brasileira, entre os estados do Amapá e Santa Catarina.

Essa definição incorporou importantes características ambientais ao sistema, e mesmo não citando as feições lavado e apicum, deixa claro que o ecossistema não ocorre somente onde há vegetação típica de mangue. No artigo $3^{\circ}$, inciso X, da referida Resolução, afirma-se que os manguezais são considerados Áreas de Preservação Permanente em toda a sua extensão.

Nesse mesmo ano, o Conama aprovou a Resolução n³12, em 10 de outubro de 2002, apresentando os critérios para a realização de licenciamento ambiental nos empreendimentos de carcinicultura. $\mathrm{O}$ artigo $2^{\circ}$, afirma que esse tipo de empreendimento é vedado em áreas de manguezais.

No ano seguinte foi aprovada a Resolução Conama ${ }^{\circ} 341$, em 25 de setembro de 2003, apresentando critérios para a caracterização de atividades e empreendimentos turísticos sustentáveis, como de interesse social para fins de ocupação de dunas originalmente desprovidas de vegetação, na Zona Costeira. Essa resolução afirma que tais empreendimentos não devem ser implementados onde houver o comprometimento do ecossistema manguezal.

A Lei Federal $n^{\circ} 11.428$ de 22 de dezembro de 2006, dispõe sobre a utilização e proteção da vegetação nativa do Bioma Mata Atlântica, apresenta no seu artigo $2^{\circ}$ o manguezal como um ecossistema associado ao bioma, conferindo-lhe a mesma proteção.

A Resolução Conama ${ }^{\circ} 303 / 2002$ é tão importante que a Lei $n^{\circ} 12.651$ de 25 de maio de 2012 , que revogou o Novo Código Florestal de 1965 (Lei ${ }^{\circ}{ }^{4.771}$ ) apresenta no seu artigo $3^{\circ}$, inciso XIII, a mesma definição de manguezal citada na referida resolução. O artigo $4^{\circ}$, inciso VII, considera como Área de Preservação Permanente os manguezais em toda a sua extensão.

$\mathrm{O}$ artigo $3^{\circ}$, da Lei $\mathrm{n}^{\circ} 12.651 / 2012$, também apresenta a definição de salgado ou marisma tropicais hipersalinos (inciso XIV), apicum (inciso XV) e áreas úmidas (inciso XXV), conforme segue: 
XIV - salgado ou marismas tropicais hipersalinos: áreas situadas em regiões com frequências de inundações intermediárias entre marés de sizígias e de quadratura, com solos cuja salinidade varia entre 100 (cem) e 150 (cento e cinquenta) partes por 1.000 (mil), onde pode ocorrer a presença de vegetação herbácea específica;

XV - apicum: áreas de solos hipersalinos situadas nas regiões entre marés superiores, inundadas apenas pelas marés de sizígias, que apresentam salinidade superior a 150 (cento e cinquenta) partes por 1.000 (mil), desprovidas de vegetação vascular;

XXV - áreas úmidas: pantanais e superfícies terrestres cobertas de forma periódica por águas, cobertas originalmente por florestas ou outras formas de vegetação adaptadas à inundação; (Incluído pela Lei n ${ }^{\circ} 12.727$, de 2012).

No mesmo ano, a Lei $n^{\circ} 12.727$, de 17 de outubro de 2012, alterou a Lei $n^{\circ} 12.651 / 2012$. O primeiro parágrafo do artigo $11^{\circ}$ autoriza a prática de atividades de carcinicultura e salinas em apicuns e salgados, desde que respeitados alguns requisitos. Entre esses critérios está o respeito a absoluta integridade dos manguezais arbustivos e dos processos ecológicos essenciais a eles associados. Garantindo a sua produtividade biológica e a sua condição de berçário para os recursos pesqueiro, bem como a sadia qualidade da água e do solo, contemplando as Áreas de Preservação Permanente e o respeito às atividades tradicionais de sobrevivência das comunidades locais.

É importante destacar que, a autorização da prática de atividades de carcinicultura em áreas de apicuns e salgados, prevista na Lei $n^{\circ} 12.727 / 2012$, contraria a Resolução Conama $n^{\circ} 312 / 2002$, pois essa Resolução proibiu empreendimentos de carcinicultura em manguezais.

É possível identificar algumas contradições na Lei $n^{\circ} 12.727 / 2012$, visto que os requisitos definidos na lei deveriam impedir qualquer ocupação em áreas de apicuns, pois os manguezais arbustivos, conforme definido no artigo $11^{\circ}$, utilizam essas áreas nos seus processos ecológicos essenciais. Da mesma forma que só será garantida a qualidade da água e do solo nesses ambientes, se suas áreas não forem utilizadas para empreendimentos de carcinicultura e salinas, devendo permanecer conservadas.

Não menos importante, o uso cultural e a sobrevivência das comunidades tradicionais só poderão ser realizados nos manguezais, em toda a sua extensão, se esses ambientes forem conservados. A contradição está no fato de que a referida Lei $\mathrm{n}^{\circ} 12.727 / 2012$ atrela a prática das atividades de carcinicultura e salinas seguindo os requisitos determinados na própria lei, esses mesmos critérios impossibilita esses empreendimentos de se estabelecerem nesse ambiente.

Ainda em relação a Lei Federal $n^{\circ} 12.651 / 2012$, especialistas consideram que a definição de manguezal deveria ter incluído as feições lavado e apicum. Essas feições fazem parte do ecossistema, conforme afirmado por Schaeffer-Novelli et al. (2012, p. 23).

Manguezal - ecossistema que coloniza depósitos sedimentares costeiros (vasas lamosas, argilosas ou arenosas) até o limite superior das preamares equinociais; e pode apresentar estrutura caracterizada por um continuum de feições: lavado, mangue e apicum. Como lavado, considera-se a feição exposta à maior frequência de inundação, apresentando substrato lodoso ou areno-lodoso exposto desprovido de qualquer cobertura vegetal vascularizada. A feição mangue apresenta cobertura vegetal típica, constituída por espécies arbóreas que lhe conferem fisionomia peculiar. Enquanto a feição apicum limita-se à feição mangue, atingida pelas águas estuarinas ou marinhas nas preamares de sizígia, equinociais e/ou empilhadas por eventos meteorológicos (elevando sua amplitude). A ocorrência de apicuns está associada, em parte, à existência de déficit hídrico. $\mathrm{O}$ apicum, ou salgado, pode apresentar-se hipersalino, limitando a ocorrência de espécies arbóreas vasculares e dando falsa impressão de que não faz parte do manguezal e que nele não há vida. Por outro lado, algumas espécies vegetais rasteiras, podem cobrir uma parte significativa do substrato dos apicuns.

De acordo com Schaeffer-Novelli et al. (2012) a definição de salgados, marismas tropicais e apicuns não está clara na Lei $n^{\circ} 12.651 / 2012$, primeiramente porque separa esses ambientes, o que não está correto. Os apicuns podem ser hipersalinos e sem vegetação arbórea, mas é uma parte do sistema manguezal, uma área muito importante, que serve como reserva de nutrientes, ocupada por diferentes espécies da fauna e colonizada, por vezes, por vegetação herbácea, além de só ocorrer quando associado ao ecossistema manguezal, sendo uma das suas feições. A Lei $n^{\circ} 12.651 / 2012$, também não apresenta o lavado como uma feição do manguezal, área de substrato lodoso exposta a inundação diária das marés, localizada na frente do bosque, sem cobertura de vegetação vascular. 
Evidencia-se ainda, que os dispositivos legais brasileiros não podem contrariar os tratados internacionais em que o Brasil é signatário, assim como a Constituição Federal. Dessa forma, todo e qualquer dispositivo em relação ao meio ambiente deve ter como referência a Carta Magna.

A partir da análise desses instrumentos legais percebe-se o conflito nas legislações apresentadas, referente ao conceito de manguezal. Frente a posição adotada pelo Ministério do Meio Ambiente, em revogar a Resolução Conama $n^{\circ} 303 / 2002$, que define os parâmetros e limites para as Áreas de Preservação Permanente, incluindo os manguezais. Torna-se urgente a análise desse instrumento legal, tão importante para salvaguardar a proteção a esse ecossistema, conforme propõe o presente artigo.

\section{Conhecendo o CONAMA}

O Conselho Nacional do Meio Ambiente (CONAMA) foi criado em 1981, com objetivo de constituir uma câmara técnica com representantes do governo federal, estados, municípios, sociedade civil e empresários, para propor estratégias e regulamentação que intentem a conservação do meio ambiente e o desenvolvimento sustentável.

Este colegiado se configurou como o principal órgão do Ministério do Meio Ambiente e formulou, durante quase quatro décadas, diferentes resoluções protetivas ao meio ambiente. É o principal órgão consultivo do Ministério do Meio Ambiente, responsável por estabelecer critérios para o licenciamento ambiental, controle e manutenção da qualidade do meio ambiente. De acordo com a Lei Federal n6.938/1981, que dispõe sobre a Política Nacional do Meio Ambiente, artigo $6^{\circ}$ inciso II, o Conama é o órgão consultivo e deliberativo:

(...) com a finalidade de assessorar, estudar e propor ao Conselho de Governo, diretrizes de políticas governamentais para o meio ambiente e para os recursos naturais e deliberar, no âmbito de sua competência, sobre normas e padrões compatíveis com o meio ambiente ecologicamente equilibrado e essencial à sadia qualidade de vida.

Em 28 de maio de 2019, houve uma reestruturação do Conama, com a diminuição do corpo de conselheiros de 96 para 23 representantes. Essa diminuição de membros ocorreu por meio do Decreto $\mathrm{n}^{\circ}$ 9.806/2019 do Ministro do Meio Ambiente que preside o Conama.

Com essa reestruturação as entidades da sociedade civil, que possuíam vinte e duas cadeiras representantes passaram a ter somente quatro. Antes da reestruturação, cada estado e o Distrito Federal contavam com uma cadeira no conselho, totalizando vinte e sete representantes, agora são somente cinco, uma para cada região geográfica do país. Os municípios que possuíam oito representantes, agora possuem somente dois. Além do setor empresarial composto por dois representantes. O Ministério Público Federal continua membro do conselho, mas sem direito a voto.

Diante dessas mudanças é preciso compreender as ações institucionais das alterações das normas de proteção, além de avaliar os impactos dessas transformações, que modificaram a ordem dos agentes públicos, da participação da sociedade, nos conselhos definidos em Lei, assim como os rebatimentos sobre o avanço da degradação ambiental.

\subsection{O caso da Resolução Conama $n^{\circ} 303 / 2002$ e os manguezais}

A Resolução Conama $n^{\circ} 303 / 2002$ dispõe sobre parâmetros, definições e limites referentes às Áreas de Preservação Permanente (APP), sendo o único instrumento legal protetivo as áreas de nascentes, veredas, montanhas, restingas, manguezais e dunas. $\mathrm{O}$ artigo $2^{\circ}$, deste dispositivo, apresenta as definições destes conceitos e o artigo $3^{\circ}$ delimita as APPs.

De acordo com essa Resolução, os manguezais são considerados APPs em toda sua extensão e as restingas na faixa mínima de trezentos metros, medidos a partir da linha de preamar máxima e em qualquer extensão, quando recoberta por vegetação, devido a função fixadora de dunas ou estabilizadora de mangues.

De acordo com o artigo $3^{\circ}$, inciso II da Lei ${ }^{\circ} 12.651 / 2012$, as APPs são consideradas áreas protegidas “(...) coberta ou não por vegetação nativa, com a função ambiental de preservar os recursos hídricos, a paisagem, a estabilidade geológica e a biodiversidade, facilitar o fluxo gênico de fauna e flora, proteger o solo e assegurar o bem-estar das populações humanas".

Os manguezais, além de serem considerados APPs, apresentam inúmeros serviços ecossistêmicos. Entre as suas funções ecológicas pode-se destacar a de berçário natural, visto que grande parte das espécies 
marinhas, que possuem importância econômica passam uma fase da sua vida nas áreas de manguezais, seja na etapa de reprodução, primeiros estágios de vida, desenvolvimento ou utilizando os manguezais como fonte de alimentação e proteção (SOUSA et al., 2016).

Outro serviço ecossistêmico prestado pelos manguezais é de manutenção da linha de costa, atenuando os processos erosivos. A energia das ondas é dissipada nos manguezais, o sistema reduz a vulnerabilidade apresentada pela zona costeira frente ao aumento do Nível Médio Relativo do Mar (NMRM) e aos eventos extremos como tempestades, furacões e tsunamis, pois servem como redutor desses impactos (IMBERT, 2018; HOCHARD; HAMILTON; BARBIER, 2019; LUNGHINO, et al., 2020; SAINTILAN et al., 2020; VALLE, et al., 2020).

Os manguezais funcionam como filtros biológicos, suas raízes e troncos retém os sedimentos carreados pelas bacias hidrográficas, esse processo também retém esgotos e poluentes. Esse material fica aprisionado nos manguezais e não contamina as águas ao redor desse sistema (MUKHERJEE et al., 2014).

Um dos ecossistemas que mais absorvem carbono da atmosfera e armazena esse elemento, em forma de biomassa e no solo, são os manguezais (LUCAS, et al., 2007; BARBIER et al., 2011; ROVAI et al., 2021). De acordo com o Atlas dos Manguezais do Brasil, quando se refere ao estoque total de carbono no sistema manguezal, inclui tanto o estoque presente no solo, quanto os dados de biomassa aérea e subterrânea, a extensão que esse sistema ocupa é representativamente maior do que qualquer outra floresta terrestre do mundo (ICMBio, 2018). Dessa forma, auxiliam na diminuição do aquecimento global, reduzindo a quantidade de carbono na atmosfera, um dos gases promotores do efeito estufa.

Outro serviço ecossistêmico promovido pelos manguezais são os usos culturais, educacionais e cênicos da sua paisagem, esse último muito utilizado pelo setor do turismo, que promove visitas de contemplação e vivências nesse ecossistema (QUEIROZ; MEIRELES; HERAS, 2012; MUKHERJEE et al., 2014). A Figura 1 apresenta uma síntese dos serviços ecossistêmicos promovidos pelos manguezais.

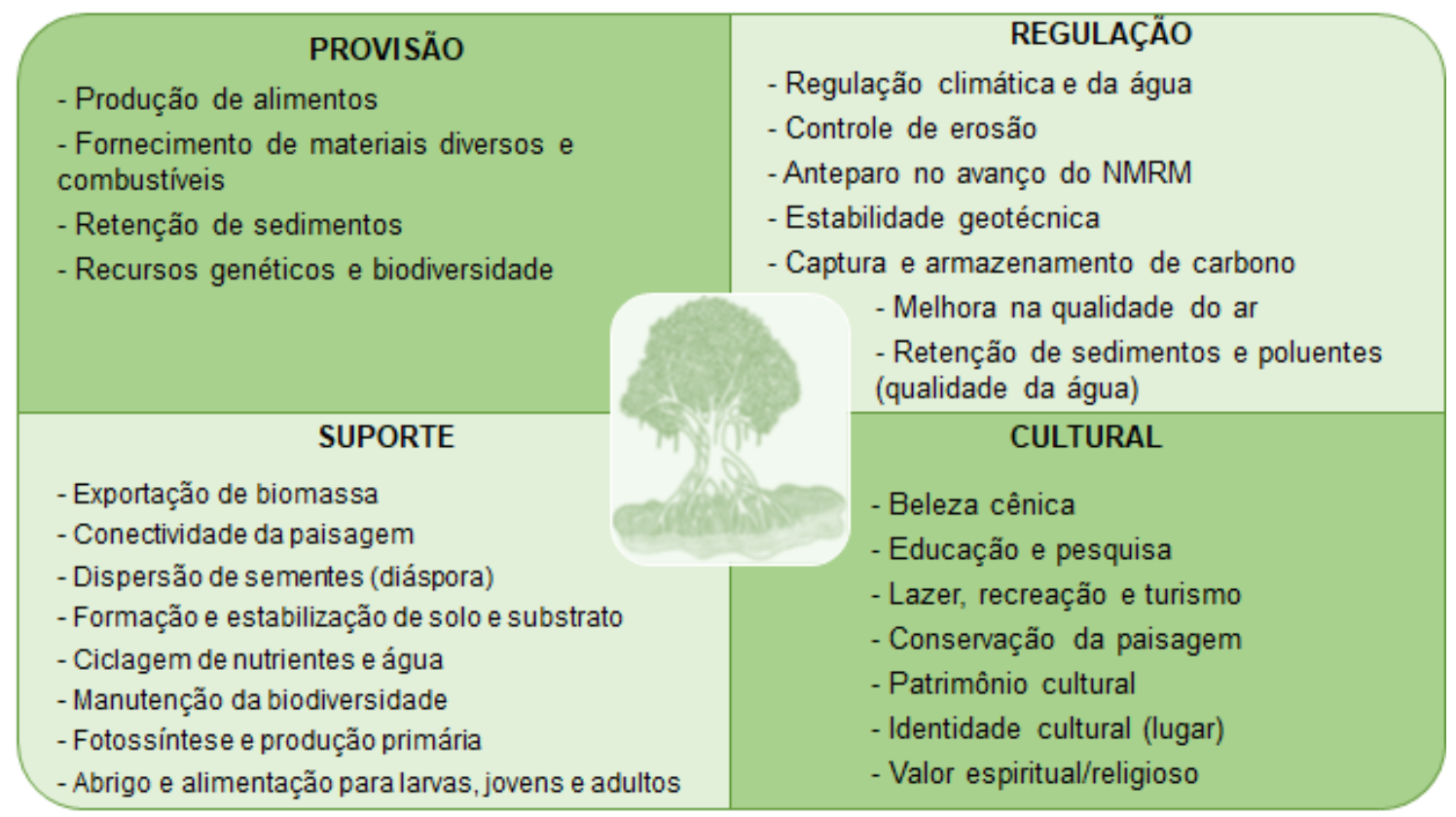

Figura 1: Serviços Ecossistêmicos nos Manguezais.

Fonte: MEA, 2005; Mukherjee et al., 2014. Organização presente artigo.

\section{Resultados e discussão}

Diante do exposto e considerando o princípio legal do não retrocesso, quando não se pode retroagir a um patamar de garantias anteriores. Entende-se que não é aceitável que uma nova norma jurídica reduza os direitos fundamentais já alcançados pela coletividade. Portanto, uma política ambiental já conquistada anteriormente não pode ser diminuída ou destruída pela atual gestão (ROTHENBURG, 2012). Passa-se a analisar a tendência de revogação de dispositivos legais do Conama, apresentando inicialmente as resoluções revogadas e na sequência detalhando a Resolução n³03/2002. 


\subsection{Revogação das Resoluções Conama}

No dia 28 de setembro de 2020, durante a 135 Reunião Ordinária do Conama (CONAMA, 2020), houve uma grande alteração na legislação ambiental brasileira, caracterizando prejuízo para as normas de proteção ao meio ambiente. Nessa reunião foi aprovada a Resolução Conama ${ }^{\circ} 500$, de 19 de outubro de 2020, que revogou as Resoluções n²84/2001, 302/2002 e 303/2002.

A Resolução Conama n²84/2001 trata do licenciamento ambiental para projetos de irrigação, definindo normas para o uso da água nesses projetos e padronizando o licenciamento ambiental. A revogação foi aceita por treze votos a favor e somente seis contrários. Com essa decisão foi retirada a obrigatoriedade da execução do licenciamento ambiental para uso dos recursos hídricos no agronegócio.

A Resolução Conama n³02/2002 se refere a preservação de áreas no entorno de reservatórios d'água. Sua revogação foi aprovada com dezessete votos a favor e somente dois contrários. Dessa forma, foi extinta as regras que definiam os limites de Áreas de Preservação Permanente (APP) em reservatórios artificiais, como o regime de uso do entorno desses reservatórios, que garantia a preservação dessa área e a qualidade da água. Possibilitando a expansão imobiliária nas áreas de entorno desses lagos e represas, favorecendo a intensa ocupação e comprometendo a qualidade da água desses ecossistemas. Água que também é utilizada para abastecimento da população em muitos casos.

A Resolução Conama n³03/2002 trata da definição das APPs, entre elas as ocorridas na faixa de trezentos metros na zona costeira, abrangendo áreas de restingas e os manguezais em toda a sua extensão. Com a sua revogação passa a não haver mais parâmetros e limites para as APPs, facilitando a especulação imobiliária na zona costeira e a ocupação dessas áreas por inúmeros empreendimentos, inclusive pela carcinicultura em áreas de manguezais.

Essas revogações ocorreram por ampla aprovação dos membros da atual configuração do Conama, composto por vinte e um representantes, além do próprio presidente, Ministro do Meio Ambiente. Nessa reunião faltaram dois votos de entidades da sociedade civil, que se encontram vagas, pois não foram substituídas após a saída da Associação Rare do Brasil e da Comissão Ilha Ativa.

Votaram a favor da revogação da Resolução Conama n³03/2002 os representantes da Casa Civil da Presidência da República, Ministério da Agricultura, Pecuária e Abastecimento, Ministério do Desenvolvimento Regional, Ministério da Economia, Ministério de Infraestrutura, Ministério de Minas e Energia, Secretaria de Governo da Presidência da República e surpreendentemente o representante do Instituto Brasileiro do Meio Ambiente e dos Recursos Naturais Renováveis - IBAMA.

Também votaram a favor dessa revogação os representantes da classe empresarial: Confederação da Agricultura e Pecuária do Brasil e Confederação Nacional da Indústria. Assim como os representantes dos estados de Mato Grosso do Sul e do Rio de Janeiro. Totalizando doze votos a favor da revogação.

Somente os representantes dos estados do Piauí, Tocantins e Rio Grande do Sul, também os representantes dos municípios de Porto Alegre e Belém, além dos dois membros da sociedade civil: Instituto Internacional de Pesquisa e Responsabilidade Socioambiental Chico Mendes e a Associação Novo Encanto de Desenvolvimento Ecológico, foram contrários, compondo sete votos.

O representante da Associação Novo Encanto de Desenvolvimento Ecológico Carlos Teodoro Irigaray tentou adiar a votação com um pedido de vista, mas o pedido não foi aceito, ele afirmou em reunião: -"Penso que essa revogação vai causar prejuízo ambiental muito maior do que eventual ganho por suprir algumas inconsistências que a resolução apresente com a legislação em vigor" (CONAMA, 2020).

De acordo com o Ministério do Meio Ambiente, as Resoluções Conama n³02 e 303 já estão contempladas na Lei Federal $n^{\circ} 12.651 / 2012$. Em sua afirmação argumenta-se que essa resolução foi criada para regulamentar o Novo Código Florestal (Lei Federal n4.771/1965), mas com a revogação dessa lei, após a aprovação da Lei Federal $n^{\circ} 12.651 / 2012$, as resoluções também deveriam ser revogadas. Entretanto, essa não é a opinião de especialistas em meio ambiente e do próprio Ministério Público Federal.

Deve ser ressaltado que tanto o Novo Código Florestal de 1965 (Lei Federal n4.771) quando a Lei Federal $n^{\circ} 12.651 / 2012$ não estabelecem a Área de Preservação Permanente em uma faixa mínima de trezentos metros da linha de preamar máxima, como proposto na Resolução Conama n³03/2002. O que está previsto é a existência de APPs nas áreas com vegetação de restingas, exclusivamente quando possuírem função fixadora de dunas ou estabilizadoras de mangue. Reafirma-se a importância da Resolução n³03/2002 para a proteção dessa faixa delimitada geograficamente de trezentos metros da linha de preamar. 
A representante do Ministério Público Federal, presente na referida reunião, Procuradora da República Fátima de Souza Borghi, alertou para a necessidade de uma maior discussão e análise sobre o tema. Sem direito a voto no conselho afirmou em reunião que: -"É toda eivada de inconstitucionalidade e ilegalidade o que está aqui acontecendo. Reitero que o Ministério Público Federal tomará as providências cabíveis" (CONAMA, 2020).

\subsection{Quem ganha e quem perde com a revogação da Resolução Conama $n^{\circ} 303 / 2002$ ?}

A configuração do Conama, após o Decreto $n^{\circ} 9.806 / 2019$, deixou o governo com pleno controle do órgão, possibilitando articular votações que vão ao encontro da atual política ambiental do governo federal.

A revogação das Resoluções Conama, ocorridas em 28 de setembro de 2020, fragilizou e abriu precedentes na proteção ambiental do país. No caso da zona costeira, alguns empreendimentos foram licenciados seguindo as orientações da Resolução Conama n³03/2002, o que não vai mais acontecer com a revogação e isso pode gerar processos de judicialização.

Em uma tentativa de reverter essa revogação, no dia 29 de setembro de 2020, a Juíza Federal Maria Amélia Almeida Senos de Carvalho, da $23^{\mathrm{a}}$ Vara Federal Criminal, assinou o Despacho/Decisão a favor da Ação Popular n`5067634-55.2020.4.02.5101/RJ, com o objetivo de suspender a anulação da revogação das Resoluções Conama n³02 e 303 de 2002. De acordo com a referida Ação Popular, a revogação contraria o artigo $225^{\circ}$ da Constituição Federal de 1988; a Política Nacional do Meio Ambiente; a Lei Federal $\mathrm{n}^{\circ} 6.938 / 1981$ e a Lei Federal $\mathrm{n}^{\circ} 12.651 / 2012$, devido ao evidente risco de danos irrecuperáveis ao meio ambiente.

Entretanto, essa suspensão só permaneceu até o dia 02 de outubro de 2020, quando o Desembargador Federal Marcelo Pereira da Silva, do Tribunal Regional Federal da $2^{\mathrm{a}}$ Região (TRF-2), aceitou o recurso da União e suspendeu o Despacho/Decisão, assinado em 29 de setembro de 2020, restabelecendo os efeitos das revogações normativas ocorridas durante a $135^{\mathrm{a}}$ Reunião Ordinária (CONAMA, 2020).

Nessa decisão, argumentou-se que a Lei $n^{\circ} 12.651 / 2012$ abrange a proteção ao manguezal, prevista na Resolução Conama n³03/2002, conforme segue: "Quanto à APP de manguezal, a União Federal argumentou que houve tratamento normativo idêntico pela Lei $\mathrm{n}^{\circ} 12.651 / 2012$ ao previsto na citada Resolução $\mathrm{n}^{\circ} 303$, o que também teria ocorrido no que diz respeito ao conceito de manguezal". Ainda na referida decisão o desembargador afirma: "Quanto ao periculum in mora apontado no provimento agravado, a União Federal defendeu não haver qualquer ameaça de dano ao meio ambiente".

Novamente, como forma de reverter a decisão apresentada na $135^{\mathrm{a}}$ Reunião Ordinária (CONAMA, 2020), no dia 28 de outubro de 2020, a Ministra Rosa Weber, do Supremo Tribunal Federal (STF), suspendeu liminarmente a Resolução Conama $\mathrm{n}^{\circ} 500 / 2020$, por meio da Medida Cautelar na arguição de descumprimento de preceito fundamental 747 Distrito Federal. Dessa forma, voltou a vigorar a proteção às APPs elencadas na Resolução Conama n³03/2002, até o julgamento pelo Plenário da Corte. Na decisão, a Ministra defendeu a necessidade de haver parâmetros mensuráveis para a proteção do meio ambiente, para que se cumpra a legislação brasileira e os compromissos firmados internacionalmente, conforme segue:

A Resolução CONAMA n³03/2002 dispõe sobre parâmetros, definições e limites de Áreas de Preservação Permanente. Tem fundamento normativo não só na Lei nº.771/1965, revogada, mas também na Lei ${ }^{\circ} 9.433 / 1997$, que institui a Política Nacional de Recursos Hídricos, nas responsabilidades do Estado brasileiro em face da Convenção da Biodiversidade, de 1992, da Convenção de Ramsar, de 1971, e da Convenção de Washington, de 1940, nos compromissos assumidos na Declaração do Rio de Janeiro, de 1992, e nos deveres impostos ao Poder Público pelos arts. $5^{\circ}$, caput e XXIII, 170, VI, 186, II, e 225 , caput e $\S 1^{\circ}$, da Constituição da República. (...)

O Estado brasileiro tem o dever - imposto tanto pela Constituição da República quanto por tratados internacionais de que é signatário - de manter política pública eficiente de defesa e preservação do meio ambiente ecologicamente equilibrado, bem como de preservar e restaurar os processos ecológicos essenciais. Ao estabelecer parâmetros normativos definidores de áreas protegidas, o Poder Público está vinculado a fazê-lo de modo a manter a integridade dos atributos ecológicos que justificam a proteção desses espaços territoriais. (...) No caso dos ecossistemas e feições naturais típicos da Zona Costeira, tais como recifes, parcéis, praias, restingas, dunas e manguezais, a previsão de normas protetivas, pelo CONAMA, encontra abrigo, outrossim, nos arts. $3^{\circ}, 5^{\circ}$ e $6^{\circ}$ da Lei $n^{\circ} 7.661 / 1988$, que institui o Plano Nacional de Gerenciamento Costeiro. Há de se observar, também, que, mediante o Decreto $\mathrm{n}^{\circ} 1.905 / 1996$, foi promulgada no Brasil a Convenção sobre Zonas 
Úmidas de Importância Internacional, de 1971, pela qual o Estado brasileiro assumiu o compromisso de proteger áreas de pântano, charco, turfa ou água, naturais ou artificiais, e em especial aquelas que servem de habitat para aves migratórias.

Verifica-se, assim, que a revogação de normas operacionais fixadoras de parâmetros mensuráveis, tal como se deu, sem que se procedesse à sua substituição ou atualização, compromete não apenas o cumprimento da legislação como a observância de compromissos internacionais. O ímpeto, por vezes legítimo, de simplificar o direito ambiental por meio da desregulamentação não pode ser satisfeito ao preço do retrocesso na proteção do bem jurídico.

(...) Tenho por suficientemente evidenciado, pois, pelo menos em juízo preliminar, que a Resolução ${ }^{\circ} 500$, de 28 de setembro de 2020, do Conselho Nacional do Meio Ambiente (CONAMA), ao revogar as Resoluções n's 284/2001, 302/2002 e 303/2002, vulnera princípios basilares da Constituição, sonega proteção adequada e suficiente ao direito fundamental ao meio ambiente equilibrado nela assegurado e promove desalinho em relação a compromissos internacionais de caráter supralegal assumidos pelo Brasil e que moldam o conteúdo desses direitos.

No dia 27 de novembro de 2020, quase dois meses depois de ocorrida a $135^{\circ}$ Reunião do Conama, o STF avaliou a suspensão da Resolução Conama $n^{\circ} 500 / 2020$. Entrou na pauta do STF a liminar concedida pela Ministra Rosa Weber no final de outubro, por unanimidade o plenário do STF decidiu suspender os efeitos da Resolução n500/2020, até o julgamento do mérito desta ação. Sem data para acontecer até a conclusão deste artigo.

Com essa decisão voltou a vigorar as Resoluções n ${ }^{\circ} 284 / 2001,302 / 2002$ e 303/2002. Na justificativa o STF afirmou que até existem outras normas de proteção aos ecossistemas apresentados nas resoluções, entretanto, nenhuma dessas normas detalha os critérios de proteção como faz as resoluções citadas. Além disso, não se pode apenas revogar normas protetivas, sem a sua substituição ou atualização, comprometendo a proteção ambiental brasileira e o cumprimento dos compromissos assumidos internacionalmente.

Mesmo amparado pela legislação ambiental, considerados Áreas de Preservação Permanentes desde o Novo Código Florestal de 1965, os manguezais sentiram o impacto da intensa ocupação costeira ao longo da história. Dessa forma, podemos considerar que os interesses econômicos preponderaram em detrimento da conservação desses ambientes naturais, mesmo apresentando importantes serviços ecossistêmicos. Portanto, o setor econômico da construção civil, mercado imobiliário, empresas de carcinicultura e infraestrutura portuária, são os setores que ganham com a revogação da Resolução Conama n³03/2002.

No momento histórico em que vivemos, a retirada de legislações protetivas ao meio ambiente se apresenta como uma perda irreparável, visto o forte impacto gerado aos ambientes relacionados por essa resolução, especialmente aos manguezais e restingas. Pois, mesmo havendo outras normas de proteção, a Resolução Conama n³03/2002 é o único instrumento jurídico que apresenta critérios específicos de proteção a esses ecossistemas, visto que limita qualquer ação nas Área de Preservação Permanentes de trezentos metros da faixa de preamar e nos manguezais em toda a sua extensão.

Desse modo, são os ecossistemas costeiros quem mais perdem com essa revogação e consequentemente as populações que fazem uso desses ambientes, conforme segue:

1) Perda de habitat para a fauna e flora costeira, podendo ocasionar até a extinção de espécies, pois a base da teia alimentar costeira será afetada (ICMBio, 2018; HAYASHI et al., 2019).

2) Detrimento do berçário natural. Os manguezais são importantes para inúmeras espécies da fauna, que passam pelo menos uma parte da sua vida nos manguezais. A maioria dessas espécies vão até o manguezal para se reproduzir, seus filhotes ficam nesse ambiente na fase juvenil, se protegendo de predadores e se alimentando com a rica oferta de nutrientes, por isso é considerado um berçário natural (SOUSA et al., 2016; ICMBio, 2018).

3) Redução de áreas de pousio, descanso e alimentação para aves migratórias, prejudicando a migração dessas aves e contribuindo para sua extinção (PURIFY et al., 2019).

4) Danos para a conservação da fauna marinha. Com a diminuição dos manguezais muitas espécies não terão acesso às áreas de viveiro, proteção e alimentação, podendo ocasionar a extinção de espécies marinhas (MUKHERJEE et al., 2014; HAYASHI et al., 2019). Grande parte dessas espécies são utilizadas para consumo humano, podendo haver privação de alimentos para as populações que fazem uso deste recurso. 
5) Diminuição dos recursos alimentares costeiros e marinhos, impactando tanto as comunidades tradicionais, que sobrevivem com essa alimentação e renda: pesca e coleta de animais (SOUSA et al., 2016; HAYASHI et al., 2019); quanto para a indústria e comércio que utilizam esses animais como matéria prima para suas atividades.

6) Detrimento do filtro natural, com os poluentes chegando de forma mais intensa nos ambientes costeiros e marinhos. Os manguezais funcionam como filtro biológico, recebendo os sedimentos, esgotos e poluentes carreados pelas bacias hidrográficas e estabilizando-os (MUKHERJEE et al., 2014).

7) Restrição da função de barreira física, pois ao reter os sedimentos carreados pelas bacias hidrográficas, o manguezal também está exercendo uma importante função ambiental, fixando os sedimentos antes de chegarem ao mar. Funcionando como barreira física para esses sedimentos, garantindo a qualidade da água na zona costeira e protegendo a foz dos rios de assoreamento (BARBIER et al., 2013; SCHAEFFER-NOVELLI et al., 2016).

8) Intensificação dos processos erosivos costeiros. Os manguezais atenuam o efeito da erosão costeira promovida pela energia que vem do mar, por meio de ondas e eventos extremos como tempestades, ressacas e tsunamis (IMBERT, 2018; HOCHARD; HAMILTON; BARBIER, 2019; LUNGHINO et al., 2020; VALLE et al., 2020). Sem a proteção dos manguezais a erosão costeira terá consequências mais severas em um curto espaço de tempo. Os manguezais e as restingas funcionam como uma unidade funcional protegendo a linha de costa, servindo como barreira natural (BARBIER et al., 2013; SCHAEFFER-NOVELLI et al., 2016).

9) Aumento de gases causadores do efeito estufa. Os manguezais são as florestas que mais absorvem carbono atmosférico (BARBIER et al., 2011; ROVAI et al., 2021), sua eliminação terá consequência direta na quantidade de gases do efeito estufa presentes na atmosfera, o que poderá agravar os efeitos das mudanças climáticas.

10) Maior impacto da elevação do Nível Médio Relativo do Mar (NMRM), atingindo diretamente as cidades costeiras. A presença de ecossistemas naturais, como os manguezais e restingas, absorvem melhor esse dano, pois esses sistemas conseguem se reorganizar no ambiente. Assim, em áreas onde houver elevação do NMRM com manguezais preservados haverá possibilidade de recolonização por espécies típicas de mangue na parte interior do continente, pois a erosão causada por essa elevação irá atingir as franjas do bosque, no contato com o mar. Por isso, a importância de conservação das áreas de apicum, que servem como reservatório de nutrientes e áreas de expansão para colonização de bosques de mangue (SCHAEFFER-NOVELLI; VALE; CINTRÓN, 2015; SAINTILAN et al., 2020).

11) Perda de áreas importantes para cultura e pesquisa. Algumas atividades humanas, principalmente as praticadas por comunidades tradicionais, estão diretamente relacionadas a esse ecossistema, como práticas sagradas e de subsistência, atividades turísticas e de educação ambiental, além de pesquisas científicas, que serão diretamente impactadas com a diminuição desse ambiente (QUEIROZ; MEIRELES; HERAS, 2012).

12) Favorecimento da especulação imobiliária na faixa de $\mathbf{3 0 0}$ metros da zona costeira, em áreas de restingas e manguezais. Essas áreas poderão ser ocupadas por empreendimentos imobiliários e também por empresas para a produção de camarão (ICMBio, 2018).

Ao longo das últimas décadas a sociedade contemporânea vem discutindo em fóruns internacionais, diferentes ações para diminuir a degradação dos ambientes naturais. O Brasil é signatário de alguns acordos, sendo os manguezais protegidos por tratados internacionais como a Convenção de Washington, 1948 (Decreto Federal n58.054/1966); a Convenção de Ramsar, 1971 (Decreto Federal n $1.905 / 1996$ ); a Convenção da Diversidade Biológica, 1992 (Decreto Federal n².519/1998) e o Acordo de Paris, 2015.

A Convenção sobre Zonas Úmidas de Importância Internacional, ocorrida em 02 de fevereiro de 1971, na cidade de Ramsar, no Irã, conhecida como Convenção de Ramsar, propõe que os países signatários firmam compromisso de proteger as áreas úmidas, incluindo os manguezais, por meio de uma gestão internacional. Essa convenção é muito importante na proteção das zonas úmidas em todo o mundo, especialmente para a proteção da avifauna migratória, que necessita desses habitats para sobreviver e realizar a migração.

Verifica-se que a revogação das Resoluções Conama contraria tanto o artigo $225^{\circ}$ da Constituição Federal, quanto compromete os compromissos assumidos pelo Brasil perante as convenções internacionais. 


\section{Conclusões}

A Constituição Federal Brasileira apresenta a Mata Atlântica e a Zona Costeira como Patrimônio Nacional, sendo que a sua utilização deve ocorrer "na forma da lei, dentro de condições que assegurem a preservação do meio ambiente, inclusive quanto ao uso dos recursos naturais". Dessa forma, é muito importante a existência das diretrizes presentes na Resolução Conama $n^{\circ} 303 / 2002$, visto que essa resolução tem força de lei e não permite a ocupação das áreas de manguezais, pois considera esses ambientes como Áreas de Preservação Permanente em toda a sua extensão.

Devido às suas características e importância, o Bioma Mata Atlântica é objeto de uma legislação particular para a sua proteção, Lei Federal n $11.428 / 2006$. Entretanto, essa lei não impede a supressão dos seus remanescentes, também não estabelece de forma direta o território para conservação dos ecossistemas associados (restingas e manguezais). Assim, a Resolução Conama $n^{\circ} 303 / 2002$ se configura como um diploma legal mais protetivo aos manguezais e as restingas, do que a própria Lei da Mata Atlântica.

Reafirmamos o retrocesso que as revogações das Resoluções Conama representam para a conservação ambiental brasileira, ainda mais quando são cometidas por quem tem o dever público de proteger o meio ambiente. Não obstante, uma nova norma jurídica não pode diminuir um direito já adquirido, sem que uma nova norma substituta ou compensatória assegure essa proteção.

Portanto, sem esse diploma legal, a legislação brasileira de proteção aos ecossistemas litorâneos não é capaz de viabilizar a proteção integral a esses ambientes, fazendo-se necessária uma legislação mais restritiva.

Conclui-se, após todo o exposto, que a Resolução Conama n³03/2002 deve ser mantida, visto a relevância da proteção aos ecossistemas tratados, em especial os manguezais. Devido à importância ecológica, social e econômica que esse sistema representa para a zona costeira.

\section{Referências bibliográficas}

BARBIER, E. B.; HACKER, S. D.; KENNEDY, C.; KOCH, E. W.; STIER, A. C.; SILLIMAN, B. R. The value of estuarine and coastal ecosystem services. Ecological Monographs, v. 81, n. 2, p. 169-193, may 2011. DOI: $10.1890 / 10-1510.1$

BARBIER, E. B.; GEORGIOU, I. Y.; ENCHELMEYER, B.; REED, D. J. The value of wetlands in protecting southeast Louisiana from hurricane storm surges. PloS One, v. 8, n. 3, p. 1-6, mar. 2013. DOI: 10.1371/journal.pone.0058715

BRASIL. Decreto Federal $\mathbf{n}^{\circ} \mathbf{4 . 1 0 5}$, de 22 de fevereiro de 1868. Regula a concessão dos terrenos de marinha, dos reservados nas margens dos rios e dos acrescidos natural ou artificialmente. Brasília, DF: Senado, 1868. Disponível em: http://www.planalto.gov.br/ccivil_03/decreto/1851-1899/D4105-1868.htm. Acesso em 20 de jan. 2021.

BRASIL. Decreto Federal no ${ }^{\circ} 4.596$, de 31 de dezembro de 1920. Regula o arrendamento de terrenos de mangue de propriedade da União. Brasília, DF: Senado, 1920. Disponível em: https://www2.camara.leg.br/legin/fed/decret/1920-1929/decreto-14596-31-dezembro-1920-776368publicacaooriginal-140272-pe.html. Acesso em 20 de jan. 2021.

BRASIL. Decreto Federal n²3.793, de 23 de janeiro de 1934. Aprova o Código Florestal. Diário Oficial da União, seção 1, Brasília, DF, p. 2882, 09 fev. 1934.

BRASIL. Decreto Federal n²4.643, de 10 de julho de 1934. Decreta o Código das Águas. Diário Oficial da União, seção 1, Brasília, DF, p. 14738, 20 jul. 1934.

BRASIL. Decreto-Lei ${ }^{\circ} 9.760$, de 05 de setembro de 1946. Dispõe sobre os bens imóveis da União e dá outras providências. Diário Oficial da União, Brasília, DF, p. 12500, 06 set. 1946.

BRASIL. Lei Federal n4.771, de 15 de setembro de 1965. Institui o Novo Código Florestal. Diário Oficial da União, seção 1, Brasília, DF, p. 9529, 16 set. 1965. 
BRASIL. Decreto Federal n58.054, de 23 de março de 1966. Promulga a Convenção para a proteção da flora, fauna e das belezas cênicas dos países da América. Diário Oficial da União, seção 1, Brasília, DF, p. 3348, 30 mar. 1966.

BRASIL. Lei Federal $n^{\circ} 6.938$, de 31 de agosto de 1981. Dispõe sobre a Política Nacional do Meio Ambiente, seus fins e mecanismos de formulação e aplicação, e dá outras providências. Diário Oficial da União, seção 1, Brasília, DF, p. 16509, 02 set. 1981.

BRASIL. Resolução Conama nº 4, de 18 de setembro de 1985. Brasília, DF: Ministério do Meio Ambiente, 1985. Disponível em: https://acervo.socioambiental.org/sites/default/files/documents/J0D00012.pdf. Acesso em 20 de jan. 2021.

BRASIL. [Constituição (1988)]. Constituição da República Federativa do Brasil. Brasília, DF: Senado Federal, 2016. 496 p. Disponível em: https://www2.senado.leg.br/bdsf/bitstream/handle/id/518231/CF88_ Livro_EC91_2016.pdf. Acesso em: 20 jan. 2021.

BRASIL. Lei Federal nº7.661, de 16 de maio de 1988. Institui o Plano Nacional de Gerenciamento Costeiro e dá outras providências. Diário Oficial da União, seção 1, Brasília, DF, p. 8633, 18 mai. 1988.

BRASIL. Decreto Federal $n^{\circ} 750$, de 10 de fevereiro de 1993. Dispõe sobre o corte, a exploração e a supressão de vegetação primária ou nos estágios avançado e médio de regeneração da Mata Atlântica, e dá outras providências. Diário Oficial da União, seção 1, Brasília, DF, p. 1801, 11 fev. 1993.

BRASIL. Resolução Conama $\mathbf{n}^{\circ} \mathbf{1 0}$, de $1^{\circ}$ de outubro de 1993. Estabelece os parâmetros básicos para análise dos estágios de sucessão de Mata Atlântica. Brasília, DF: Ministério do Meio Ambiente, 1993. Disponível

em: https://www.icmbio.gov.br/cepsul/images/stories/legislacao/Resolucao/1993/res_conama_10_1993_estagioss ucessaomataatlantica.pdf. Acesso em: 20 jan. 2021.

BRASIL. Decreto Federal n 1.905 , de 16 de maio de 1996. Promulga a Convenção sobre Zonas Úmidas de Importância Internacional, especialmente como Habitat de Aves Aquáticas, conhecida como Convenção de Ramsar, de 02 de fevereiro de 1971. Diário Oficial da União, seção 1, Brasília, DF, p. 8520, 17 mai. 1996.

BRASIL. Decreto Federal n².519, de 16 de março de 1998. Promulga a Convenção sobre Diversidade Biológica, assinada no Rio de Janeiro, em 05 de junho de 1992. Diário Oficial da União, seção 1, Brasília, DF, p. 1, 17 mar. 1998.

BRASIL. Lei Federal n ${ }^{\circ} 9.605$, de 12 de fevereiro de 1998. Dispõe sobre as sanções penais e administrativas derivadas de condutas e atividades lesivas ao meio ambiente, e dá outras providências. Diário Oficial da União, seção 1, Brasília, DF, p. 1, 13 fev. 1998.

BRASIL. Resolução Conama $\mathbf{n}^{\circ} \mathbf{2 8 4}$, de 30 de agosto de 2001. Dispõe sobre o licenciamento de empreendimentos de irrigação. Brasília, DF: Ministério do Meio Ambiente, 2001. Disponível em: http://www2.mma.gov.br/port/conama/legiabre.cfm?codlegi=282. Acesso em: 20 jan. 2021.

BRASIL. Resolução Conama n ${ }^{\circ}$ 302, de 20 de março de 2002. Dispõe sobre os parâmetros, definições e limites de Áreas de Preservação Permanente de reservatórios artificiais e o regime de uso do entorno. Brasília, DF: Ministério do Meio Ambiente, 2002. Disponível em: http://www2.mma.gov.br/port/conama/legiabre.cfm

?codlegi=298. Acesso em: 20 jan. 2021.

BRASIL. Resolução Conama n ${ }^{\circ} \mathbf{3 0 3}$, de 20 de março de 2002. Dispõe sobre parâmetros, definições e limites de Áreas de Preservação Permanente. Brasília, DF: Ministério do Meio Ambiente, 2002. Disponível em: http://www2.mma.gov.br/port/conama/legiabre.cfm?codlegi=299. Acesso em: 20 jan. 2021.

BRASIL. Resolução Conama n ${ }^{\circ}$ 312, de 10 de outubro de 2002. Dispõe sobre o licenciamento ambiental dos empreendimentos de carcinicultura na zona costeira. Brasília, DF: Ministério do Meio Ambiente, 2002. Disponível em: https://www.legisweb.com.br/legislacao/?id=98293. Acesso em: 20 jan. 2021. 
BRASIL. Resolução Conama $\mathbf{n}^{\circ} \mathbf{3 4 1}$, de 25 de setembro de 2003. Dispõe sobre critérios para a caracterização de atividades ou empreendimentos turísticos sustentáveis como de interesse social para fins de ocupação de dunas originalmente desprovidas de vegetação, na Zona Costeira. Brasília, DF: Ministério do Meio Ambiente, 2003. Disponível em: https://www.legisweb.com.br/legislacao/?id=99438. Acesso em: 20 jan. 2021.

BRASIL. Lei Federal n' ${ }^{\circ} 1$.428, de 22 de dezembro de 2006. Dispõe sobre a utilização e proteção da vegetação nativa do Bioma Mata Atlântica, e dá outras providências. Diário Oficial da União, seção 1, Brasília, DF, p. 1, 09 jan. 2007.

BRASIL. Lei Federal $\mathbf{n}^{\circ} \mathbf{1 2 . 6 5 1}$, de 25 de maio de 2012. Dispõe sobre a proteção da vegetação nativa; altera as Leis $n^{\circ}$ s 6.938, de 31 de agosto de 1981, 9.393, de 19 de dezembro de 1996, e 11.428, de 22 de dezembro de 2006; revoga as Leis $\mathrm{n}^{\circ}$ s 4.771, de 15 de setembro de 1965, e 7.754, de 14 de abril de 1989, e a Medida Provisória n².166-67, de 24 de agosto de 2001; e dá outras providências. Diário Oficial da União, seção 1, Brasília, DF, p. 1, 28 mai. 2012.

BRASIL. Lei Federal $n^{\circ} 12.727$, de 17 de outubro de 2012. Altera a Lei $\mathrm{n}^{\circ}$ 12.651, de 25 de maio de 2012, que dispõe sobre a proteção da vegetação nativa; altera as Leis $n^{\circ}$ s 6.938 , de 31 de agosto de 1981, 9.393, de 19 de dezembro de 1996, e 11.428, de 22 de dezembro de 2006; e revoga as Leis $n^{\circ}$ s 4.771 , de 15 de setembro de 1965, e 7.754, de 14 de abril de 1989, a Medida Provisória ${ }^{\circ}$ 2.166-67, de 24 de agosto de 2001, o item 22 do inciso II do art.167 da Lei $\mathrm{n}^{\circ} 6.015$, de 31 de dezembro de 1973, e o $\S 2^{\circ}$ do art. $4^{\circ}$ da Lei $n^{\circ}$ 12.651, de 25 de maio de 2012. Diário Oficial da União, seção 1, Brasília, DF, p. 1, 18 out. 2012.

BRASIL. Decreto Federal ${ }^{\circ} 9.806$, de 28 de maio de 2019. Altera o Decreto ${ }^{\circ}$ 99.274, de 6 de junho de 1990, para dispor sobre a composição e o funcionamento do Conselho Nacional do Meio Ambiente Conama. Diário Oficial da União, Brasília, DF, p. 1, 29 mai. 2019.

BRASIL. Resolução Conama n500, de 19 de outubro de 2020. Declara a revogação das resoluções discriminadas neste ato. Brasília, DF: Ministério do Meio Ambiente, 2020. Diário Oficial da União, seção 1, Brasília, DF, p. 88, 21 out. 2020.

CELlard, A. A análise documental. In: POUPART, J.; DESLAURIERS, J. P.; GROUlX, L. H.; LAPERRIÈRE, A.; MAYER, R.; PIRES, A. A pesquisa qualitativa: enfoques epistemológicos e metodológicos. Petrópolis: Vozes, 2008. p. 295-316.

CONAMA. Vídeo $135^{\mathrm{a}}$ Reunião Ordinária do CONAMA. Disponível em: https://www.youtube.com/watch?v=-xScCeGFUac. Acesso em: 29 set. 2020.

HAYASHI, S. N.; SOUZA-FILHO, P. W. M.; NASCIMENTO, W. R.; FERNANDES, M. E. B. The effect of antropogenic drivers on spatial patterns of mangrove land use on the Amazon coast. Plos One, v. 14, n. 6, p. 1-20, jun. 2019. DOI: 10.1371/journal.pone.0217754

HOCHARD, J. P.; HAMILTON, S.; BARBIER, E. D. Mangroves shelter coastal economic activity from cyclones. PNAS, v. 116, n. 25, p. 12232-12237, jun. 2019. DOI: 10.1073/pnas. 1820067116

ICMBio, Instituto Chico Mendes de Conservação da Biodiversidade. Atlas dos Manguezais do Brasil. Brasília: ICMBio, 2018. 176 p.

IMBERT, D. Hurricane disturbance and forest dynamics in east Caribbean mangroves. Ecosphere, v. 9, n. 7 , p. 1-13, jul. 2018. DOI: $10.1002 /$ ecs 2.2231

LUCAS, R. M.; MITCHELL, A. L.; ROSENQVIST, A.; PROISY, C.; MELIUS, A.; TICEHURST, C. The potential of L-band SAR for quantifying mangrove characteristics and change: case studies from the tropics. Aquatic Conservation: Marine and Freshwater Ecosystems, v. 17, p. 245-264, 2007. DOI: $10.1002 / \mathrm{aqc} .833$

LUNGHINO, B.; TATE, A. F. S.; MAZEREEUW, M.; MUHARI, A.; GIRALDO, F. X.; MARRAS, S.; SUCKALE, J. The protective benefits of tsunami mitigation parks and ramifications for their strategic design. PNAS, v. 117, n. 20, p.10740-10745, may 2020. DOI: 10.1073/pnas.1911857117 
MACIEL, N. C. Legislação Ambiental e o manguezal. In: ALVES, J. R. P. (Org.) Manguezais: educar para proteger. Rio de Janeiro: FEMAR/SEMADS, 2001. p. 35-45.

MEA - Millennium Ecosystem Assessment. Ecosystems and human well-being. Washington, DC.: Island Press, 2005.

MUKHERJEE, N.; SUTHERLAND, W. J.; DICKS, L.; HUGÉ, J.; KOEDAM, N.; DAHDOUH-GUEBAS, F. Ecosystem service valuations of mangrove ecosystems to inform decision making and future valuation exercises. Plos One, v. 9, n. 9, p. 1-9, sep. 2014. DOI: 10.1371/journal.pone.0107706

POLIDORO, B. A.; CARPENTER, K. E.; COLLINS, L.; DUKE, N. C.; ELLISON, A. M.; ELLISON, J. C.; FARNSWORTH, E. J.; FERNANDO, E. S.; KATHIRESAN, K.; KOEDAM, N. E.; LIVINGSTONE, S. R.; MIYAGI, T.; MOORE, G. E.; NAM, V. N.; ONG, J. E.; PRIMAVERA, J. H.; SALMO, S. G.; SANCIANGCO, J. C.; SUKARDJO, S.; WANG, Y.; YONG, J. W. H. The loss of species: mangrove extinction risk and geographic areas of global concern. Plos One, v. 5, n. 4, p. 1-10, apr. 2010. DOI: 10.1371/journal.pone.0010095

PURIFY, A.; NURDIN' N.; MAULANI, R. I.; LANURU, M. Water bird habitat suitability analysis in an urban coastal wetland (case study: Lantebung mangrove ecotourism área). IOP Conference Series: Earth and Environmental Science, v. 370, p. 1-9, 2019. DOI: 10.1088/1755-1315/370/1/012042

QUEIROZ, L. S.; MEIRELES, A. J. A.; HERAS, S. R. Serviços ecossistêmicos costeiros e comunidades tradicionais. Revista da Associação Nacional de Pós-Graduação e Pesquisa em Geografia (ANPEGE), v. 8, n. 10, p. 145-159, ago./dez. 2012. DOI: 10.5418/RA2012.0810.0010

ROTHENBURG, W. C. Não retrocesso ambiental: direito fundamental e controle de constitucionalidade. In: BRASIL, Senado Federal. O princípio da proibição de retrocesso ambiental. Comissão de Meio Ambiente, Defesa do Consumidor e Fiscalização e Controle. Brasília: Senado Federal, 2012. p. 247-270.

ROVAI, A. S.; COELHO-JUNIOR, C.; ALMEIDA, R.; CUNHA-LIGNON, M.; MENGHINI, R. P.; TWILLEY, R. R.; CINTRÓN-MOLERO, G.; SCHAEFFER-NOVELLI, Y. Ecossystem-level carbon stocks and sequestration rates in mangroves in the Cananéia-Iguape lagoon estuarine system, southeastern Brazil. Forest Ecology and Management, v. 479, p. 1-13, jan. 2021. DOI:10.1016/j.foreco.2020.118553

SÁ-SILVA, J. R.; ALMEIDA, C. D.; GUINDANI, J. F. Pesquisa documental: pistas teóricas e metodológicas. Revista Brasileira de História \& Ciências Sociais. v. 1, n. 1, p. 1-15, jul. 2009. ISSN: $2175-3423$

SAINTILAN, N.; KHAN, N. S.; ASHE, E.; KELlEWAY, J. J.; ROGERS, K.; WOODROFFE, C. D.; HORTON, B. P. Thresholds of mangrove survival under rapid sea level rise. Science, v. 368, p. 1118-1121, jun. 2020. DOI: 10.1126/sience.aba2656

SCHAEFFER-NOVELLI, Y.; ROVAI, A. S.; COELHO-JUNIOR, C.; MENGHINI, R. P.; ALMEIDA, R. Alguns impactos do PL 30/2011 sobre os manguezais brasileiros. In: SOUZA, G.; JUCÁ, K.; WATHELY, M. (Org.) Código Florestal e a Ciência: o que nossos legisladores ainda precisam saber. Brasília - DF: Comitê Brasil. 2012. p. 18-27.

SCHAEFFER-NOVELLI, Y.; VALE, C. C.; CINTRÓN, G. Monitoramento do ecossistema manguezal: estrutura e características funcionais. In: TURRA, A.; DENADAI, M. R. (Orgs.) Protocolos para o monitoramento de habitats bentônicos costeiros. Rede de Monitoramento de Habitat Bentônicos Costeiros - ReBentos. São Paulo: IO Universidade de São Paulo, 2015. p. 62-80.

SCHAEFFER-NOVELLI, Y.; SORIANO-SIERRA, E. J.; VALE, C. C.; BERNINI, E.; ROVAI, A. S.; PINHEIRO, M. A. A.; SCHMIDT, A. J.; ALMEIDA, R.; COELHO-JUNIOR, C.; MENGHINI, R. P.; MARTINEZ, D. I.; ABUCHAHLA, G. M. O.; CUNHA-LIGNON, M.; CHARLIER-SARUBO, S.; SHIRAZAWA-FREITAS, J.; CINTRÓN-MOLERO, G. Climate changes in mangrove forests and salt marshes. Brazilian Journal of Oceanography, v. 64, n. 2, p. 37-52, 2016. DOI: 10.1590/S1679875920160919064sp2 
SOUSA. L. P.; SOUSA, A. I.; ALVES, F. L.; LILLEBO, A. I. Ecosystem services provided by a complex coastal region: challenges of classification and mapping. Scientific Reports, v. 6, p. 1-14, mar. 2016. DOI: $10.1038 /$ srep22782

VALLE, A.; ERIKSSON, M.; ISHIZAWA, O. A.; MIRANDA, J. J. Mangroves protect coastal economic activity from hurricanes. PNAS, v. 117, n. 1, p. 265-270, jan. 2020. DOI: 10.1073/pnas.1911617116

\footnotetext{
(1) (요 (2)

Este artigo é distribuído nos termos e condições do Creative Commons Attributions/AtribuiçãoNãoComercial-CompartilhaIgual (CC BY-NC-SA).
} 